\title{
An 11-year-old male patient with refractory asthma and heartburn
}

\author{
Tareq Al-Abdoulsalam MBBCh ${ }^{1}$, Mark A Anselmo MD²
}

T Al-Abdoulsalam, MA Anselmo. An 11-year-old male patient with refractory asthma and heartburn. Can Respir J 2011;18(2):81-83.

Achalasia is characterized by obstruction of the distal esophagus and subsequent dilation of the proximal esophagus, and is considered to be a rare disorder in children. Patients commonly present with gastrointestinal (GI) symptoms such as dysphagia; however, pulmonary symptoms may also occur. Rare pulmonary symptoms due to achalasia are dyspnea and wheeze due to tracheal compression. The authors describe an 11-year-old boy who was referred to a pediatric respiratory clinic for asthma that was not responsive to inhaled medications. The child presented with a one-year history of dyspnea on exertion, cough and wheeze. He also complained of chronic dyspepsia. The presence of GI symptoms, in addition to abnormalities on chest radiograph and spirometry, suggested the presence of achalasia. The diagnosis was confirmed and the patient subsequently underwent surgical myotomy that relieved his GI and pulmonary symptoms, and normalized spirometry. The present article is an illustrative case report to remind pediatricians to consider other diagnoses when a patient does not respond to asthma medications.

Key Words: Achalasia; Asthma; Pulmonary function tests; Tracheal compression

C sophageal achalasia is a motor disorder of unknown etiology charEacterized by functional obstruction of the distal esophagus, with subsequent dilation of the proximal part (1). Primary esophageal achalasia is a rare disease with a prevalence of one in 100,000 population (2). The disorder is even rarer in children, with less than $5 \%$ of all cases being recorded in this age group, and an estimated annual incidence rate of 0.11 per 100,000 children $(3,4)$. The most common presenting symptoms of achalasia are solid or liquid dysphagia, regurgitation and vomiting of undigested food, failure to thrive and chest pain $(1,5)$. The incidence of pulmonary complications such as cough and recurrent pneumonia can be up to $25 \%(6,7)$. However, mechanical tracheal compression due to a dilated esophagus in children with achalasia is rare. We conducted a literature search on MEDLINE “1950 to August week 3, 2009”, EMBASE CLASSIC \& EMBASE “1947-2009 August 27th” and PubMed, and found only a few pediatric case reports (8-15). The patients were adolescents and, aside from dysphagia and vomiting, had at least a one-year history of cough or, less commonly, wheeze. The pulmonary function tests (PFTs) were suggestive of airway obstruction, and a dilated esophagus compressing the trachea was obvious on chest radiographs. After successful treatment, the symptoms disappeared and PFTs were markedly improved.

We report a young boy with achalasia who presented primarily with exercise-induced dyspnea and wheeze. This is followed by a literature review and a discussion of esophageal achalasia.

\section{CASE PRESENTATION}

A previously healthy 11 -year-old boy presented with a one-year history of shortness of breath during exercise. This was of gradual onset and usually started within a few minutes of exertion. It was also associated with an inspiratory breathing noise, expiratory wheeze and cough

\section{Un garçon de 11 ans atteint d'asthme réfractaire et de brûlures d'estomac}

L'achalasie, considérée comme une pathologie rare chez l'enfant, se caractérise par l'obstruction de l'œsophage distal et la dilatation subséquente de l'œsophage proximal. Les patients présentent souvent des symptômes gastrointestinaux (GI) comme la dysphagie, mais des symptômes pulmonaires peuvent également se manifester. La dyspnée et la respiration sifflante attribuable à la compression trachéale sont de rares symptômes pulmonaires causés par l'achalasie. Les auteurs décrivent le cas d'un garçon de 11 ans qui a été aiguillé vers une clinique respiratoire pédiatrique en raison d'un asthme réfractaire aux médicaments en aérosol. L'enfant avait des antécédents de dyspnée à l'effort, de toux et de respiration sifflante depuis un an. Il se plaignait également de dyspepsie. La présence de symptômes GI, en plus des anomalies à la radiographie pulmonaire et à la spirométrie, laissait supposer une achalasie. Le diagnostic a été confirmé, et le patient a subi une myotomie chirurgicale qui a soulagé les symptômes GI et pulmonaires et normalisé la spirométrie. Le présent article est un rapport de cas illustratif qui rappelle aux pédiatres d'envisager d'autres diagnostics lorsqu'un patient ne répond pas aux médicaments contre l'asthme.

productive for sputum. However, there was no history of cyanosis, chest pain, palpitation or syncope. The shortness of breath was relieved with rest, but not by an inhaled short-acting beta- 2 agonist bronchodilator. The patient was also found to experience chronic heartburn sensation and occasional vomiting after meals but no other gastrointestinal (GI) symptoms. The review of systems was otherwise unremarkable. The patient was born at term in Canada and did not travel outside of North America. He did not have a personal history of atopy or allergies, tracheal intubation or trauma, or foreign body aspiration, and there were no previous hospital admissions or surgeries. He was not on regular medications except for intermittent inhaled bronchodilator before exercise, which was unhelpful. The family history and the home and school environments did not contribute to the patient's illness.

The physical examination revealed a healthy-looking boy whose weight was at the 10 th percentile, while his height was at the 50 th percentile for age and sex. The patient was breathing room air comfortably and quietly without respiratory distress. The chest morphology was normal and trachea were not deviated. There were no chest retractions and auscultation was normal. The remainder of the physical examination was unremarkable.

Spirometry revealed a forced vital capacity (FVC) of $85 \%$ predicted, a forced expiratory volume in $1 \mathrm{~s}\left(\mathrm{FEV}_{1}\right)$ of $46 \%$ predicted and an $\mathrm{FEV}_{1} / \mathrm{FVC}$ ratio of $49 \%$. Maximal expiratory and inspiratory flowvolume loop showed symmetric reduction of both maximal expiratory and inspiratory flows, a pattern that was suggestive of a fixed central airway obstruction (Figure 1). Posteroanterior and lateral chest radiographs demonstrated a second column of air in the mediastinum with an air-fluid level; however, the lung parenchyma was normal (Figure 2). An infused computed tomography (CT) scan of the chest was performed later and showed a dilated proximal esophagus compressing the trachea but no scars or chronic changes in the lung parenchyma

${ }^{1}$ Division of Respiratory Medicine, Montreal Children's Hospital of the McGill University Health Centre, Montreal, Quebec; ${ }^{2}$ Division of Respiratory Medicine, Alberta Children's Hospital, Calgary, Alberta

Correspondence: Dr Mark A Anselmo, Division of Respiratory Medicine, Alberta Children's Hospital, 2888 Shaganappi Trail Northwest, Calgary, Alberta T3B 6A8. Telephone 403-955-2483, fax 403-955-7059, e-mail mark.anselmo@albertahealthservices.ca 


\begin{tabular}{|c|c|c|c|c|c|}
\hline \multicolumn{5}{|c|}{ SPIROMETRY } & $\begin{array}{c}\text { Flow } \\
8\end{array}$ \\
\hline \multirow{8}{*}{$\begin{array}{l}\text { FVC } \\
\text { FEV1 } \\
\text { FEV1/FVC } \\
\text { FEF25-75\% } \\
\text { PEF } \\
\text { FEF/FIF50 } \\
\text { MVV }\end{array}$} & & Ref & Pre & Pre & 6 \\
\hline & Liters & 2.47 & 2.11 & $\begin{array}{r}10 \\
85\end{array}$ & 4 \\
\hline & Liters & 2.25 & 1.03 & 46 & 2 \\
\hline & & 86 & 49 & & \\
\hline & L/sec & 2.64 & 0.73 & 28 & \\
\hline & L/sec & 4.66 & 1.73 & 37 & -2 \\
\hline & $/ / \mathrm{min}$ & & 0.42 & & \\
\hline & L/mIn & 19 & & & ${ }_{-1}^{-6} \quad 0 \quad \begin{array}{c}1 \\
\text { Volume }\end{array}$ \\
\hline
\end{tabular}

Figure 1) Spirometry demonstrating an obstructive pattern in both inspiratory and expiratory loops due to fixed thoracic airways obstruction. FEF25-75\% Forced expiratory flow between $25 \%$ and $75 \%$ of forced vital capacity (FVC); FEV Forced expiratory volume in $1 \mathrm{~s}$; FIF50 Forced inspiratory flow at 50\% of FVC; Meas Measure; MVV Maximum voluntary ventilation; PEF Peak expiratory flow; Ref Reference
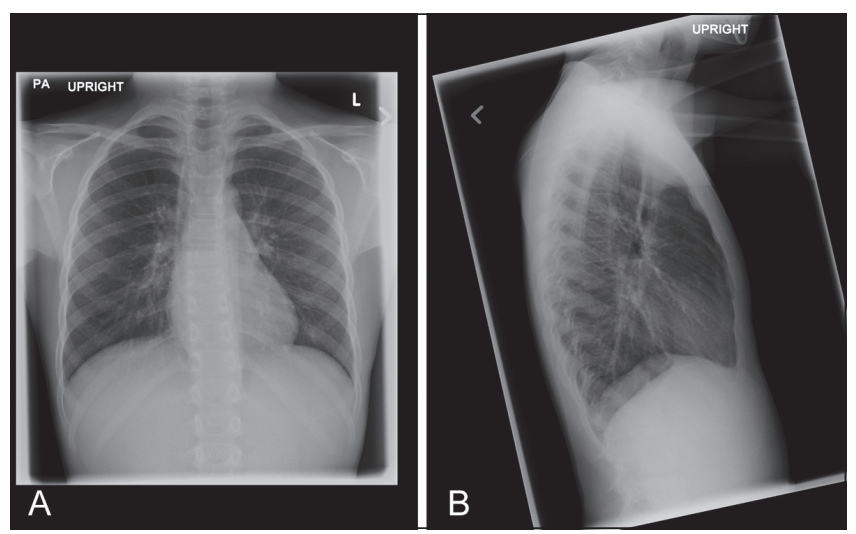

Figure 2) Chest radiographs of the patient. On the posteroanterior view (A), an air-fluid level is evident mid-line at level T7. On the lateral view (B), the same air-fluid level is visible anterior to the vertebral column. Additionally, esophageal distension is evident on the lateral view

(Figure 3). Esophageal achalasia was suspected at that point and, subsequently, confirmed by the results of esophageal manometry and upper gastrointestinal endoscopy.

Thereafter, the patient underwent an elective and successful surgical (Heller) myotomy that relieved the distal esophageal obstruction. The surgery and recovery were uneventful, and the patient did not experience respiratory compromise during or after surgery. After surgery, the GI and respiratory symptoms disappeared, and the patient began to gain weight. Follow-up PFTs performed two months after surgery showed improvement in spirometry: FVC of $87 \%$ predicted, $\mathrm{FEV}_{1}$ of $77 \%$ predicted with no significant response to inhaled bronchodilators and an $\mathrm{FEV}_{1} / \mathrm{FVC}$ ratio of $80 \%$. The maximal expiratory and inspiratory flow-volume loop improved and did not display the previously noted obstructive pattern (Figure 4). The patient's clinical and objective improvements obviated the need for further investigation, which may have included flexible bronchoscopy to assess large airway dynamics.

\section{DISCUSSION}

Primary esophageal achalasia is rare in pediatric patients. It commonly presents with GI symptoms such as dysphagia, postprandial vomiting, failure to thrive and retrosternal chest pain. Pulmonary symptoms, however, can occur and are mainly due to tracheal aspiration of the esophageal contents. Patients may present with chronic or nocturnal wet cough, episodes of persistent bronchospasm or recurrent pneumonia $(1,6,7)$. Another cause of pulmonary symptoms in patients with achalasia is tracheal compression caused by a distended esophagus,

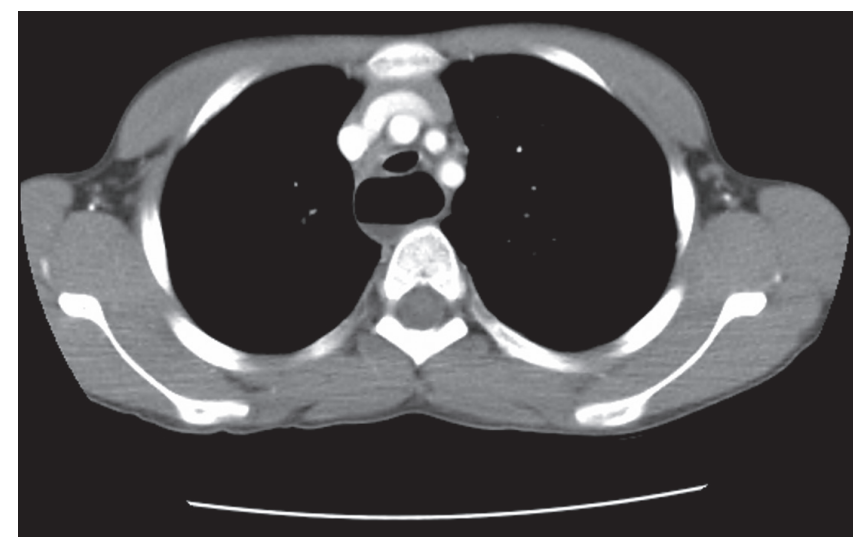

Figure 3) Contrast-enhanced thoracic computed tomography in mediastinal windows demonstrating a distended esophagus with an air-fluid level, which is compressing the trachea

\begin{tabular}{|c|c|c|c|c|c|c|c|c|c|}
\hline \multicolumn{2}{|c|}{ SPIROMETRY } & \multirow[b]{2}{*}{ Ref } & \multirow[b]{2}{*}{$\begin{array}{r}\text { Pre } \\
\text { Meas }\end{array}$} & \multirow[b]{2}{*}{$\begin{array}{r}\text { Pre } \\
\% \text { Ref }\end{array}$} & \multirow[b]{2}{*}{$\begin{array}{r}\text { Post } \\
\text { Meas }\end{array}$} & \multirow[b]{2}{*}{$\begin{array}{l}\text { Post } \\
\% \text { Ref }\end{array}$} & \multirow[b]{2}{*}{$\begin{array}{r}\text { Post } \\
\% \text { Chg }\end{array}$} & \multirow{2}{*}{\multicolumn{2}{|c|}{$\begin{array}{c}\text { Flow } \\
{ }^{8} \\
6 \\
6\end{array}$}} \\
\hline & & & & & & & & & \\
\hline FVC & Liters & 2.71 & 2.37 & 87 & 2.43 & 89 & 2 & 4 & \\
\hline FEV1 & Liters & 2.47 & 1.90 & 77 & 1.97 & 79 & 4 & 2 & \\
\hline FEV1/FVC $\%$ & & 86 & 80 & & 81 & & & & \\
\hline FEF25-75\% & L/sec & 2.87 & 1.84 & 64 & 1.91 & 67 & 4 & -2 & \\
\hline PEF & L/sec & 5.22 & 3.54 & 68 & 3.79 & 73 & 7 & -2 & \\
\hline FEF/FIF 50 & & & 0.60 & & 0.68 & & 12 & -4 & \\
\hline MVV & $\mathrm{L} / \mathrm{min}$ & 85 & & & & & & ${ }_{-1}^{-6}$ & ${ }^{0}{ }_{\text {Volume }}^{1} 23^{3} \quad 4$ \\
\hline
\end{tabular}

Figure 4) Postoperative spirometry demonstrating improved forced expiratory volume in $1 \mathrm{~s}\left(\mathrm{FEV}_{1}\right)$ and forced expiratory flow (FEF) between $25 \%$ and $75 \%$ of forced vital capacity (FVC), as well as a normal inspiratory flow loop. Chg Change; FEF25-75\% Forced expiratory flow between 25\% and 75\% of FVC; FIF50 Forced inspiratory flow at 50\% FVC; Meas Measure; MVV Maximum voluntary ventilation; PEF Peak expiratory flow; Ref Reference

which was initially reported by Bello et al (16) in 1950. Airway obstruction may manifest as dyspnea, wheeze and/or stridor. These symptoms can be insidious or acute at rest, after a meal, or during exertion and high respiratory demand.

Certain investigations are helpful in diagnosing achalasia $(1,2)$. A chest radiograph may show an air-fluid level in a dilated esophagus. A contrast esophogram may demonstrate retained food in an aperistaltic distal esophagus that exhibits a smooth taper leading to the closed lower esophageal sphincter. This radiological sign is known as 'bird's beak', and is usually indicative of esophageal achalasia. Esophageal manometry is the only test that confirms the diagnosis - evidenced by incomplete relaxation of a high-pressure lower esophageal sphincter during swallowing. Spirometry and the maximal expiratory and inspiratory flow-volume loop are important components of the pulmonary evaluation (10) in addition to radioimaging that includes chest radiograph and/or CT scan. In the presence of current and advanced imaging techniques, an initial diagnostic flexible bronchoscopy may not be necessary. Because of its rarity and nonspecific presentation, a diagnosis of achalasia may be delayed; the mean duration of symptoms before diagnosis can be up to 28 months $(1,6,7)$.

Treatment modalities used in patients with achalasia include pneumatic dilation, surgical (Heller) myotomy, botulinum toxin and pharmacological treatment $(1,2,15)$. The most effective treatment options are pneumatic dilation and surgical myotomy; however, they are associated with the risk of gastroesophageal reflux. Botulinum toxin is an expensive option and is initially effective in treating the achalasia; however, the long-term results are disappointing. Pharmacological treatment, in the form of calcium channel blockers (nifedipine) and phosphodiesterase inhibitors, offer temporary relief of dysphagia only.

Our patient was treated as an asthmatic for one year. The key point in the history, however, was the failure of inhaled short beta- 2 agonist 
bronchodilators to relieve his symptoms. Another important fact was the presence of a productive cough instead of a dry cough, which is characteristic of bronchial asthma. Although no complaints of poor appetite or weight loss were recorded, the discrepancy between his weight and height was suspicious for diagnoses other than asthma. In addition to the chest radiograph, the other clinical hint was the abnormal flow-volume loop that was typical for fixed central airway obstruction. Ideally, our patient should have undergone postbronchodilator spirometry to document a poor response to inhaled bronchodilators; however, he was exhausted and could not perform the final part of the test. We performed a chest CT scan with contrast to rule out intrathoracic tracheal compression from a congenital vascular anomaly compressing both the trachea and esophagus. Once the CT scan confirmed the absence of such lesions, and the only findings were a dilated esophagus with tracheal compression and normal lung parenchyma, the diagnosis of achalasia was considered and the patient was referred to a GI specialist who confirmed the diagnosis.

\section{SUMMARY}

Esophageal achalasia is a rare disease of childhood and may present with symptoms outside the GI system. Pediatricians and pediatric respirologists should consider it in patients who have respiratory complaints that are associated with GI symptoms. The clinician should also consider another diagnosis in a patient who has documented poor response to beta- 2 agonist bronchodilators and failure to thrive.

\section{REFERENCES}

1. Orenstein S, Peters J, Khan S, Youssef N, Hussain S. Dysmotility. In: Kliegman R, Behrman R, Jenson R, Stanton B, eds. Nelson Textbook of Pediatrics. Philadelphia: Saunders Elsevier, 2007:1545-6.

2. Clouse R, Diamant N. Esophageal motor and sensory function and motor disorder of the esophagus. In: Feldman M, Friedman L, Brandt L, Sleisenger M, eds. Sleisenger \& Fordtran's
Gastrointestinal and Liver Disease: Pathophysiology/Diagnosis/ Management. Philadelphia: Saunders Elsevier, 2006:856-904.

3. Mayberry JF, Mayell MJ. Epidemiological study of achalasia in children. Gut 1988;29:90-3.

4. Wong R, Achalasia. In: Castell D, ed. The Esophagus. Boston, Toronto, London: Little Brown \& Co, 1992:233-60.

5. Mehdi NF, Weinberger MM, Abu-Hasan MN. Achalasia: Unusual cause of chronic cough in children. Cough 2008;4:6.

6. Azizkhan RG, Tapper D, Eraklis A. Achalasia in childhood: A 20-year experience. J Pediatr Surg 1980;15:452-6.

7. Berquist WE, Byrne WJ, Ament ME, Fonkalsrud EW, Euler AR. Achalasia: Diagnosis, management, and clinical course in 16 children. Pediatrics 1983;71:798-805.

8. Chapman S, Weller PH, Campbell CA, Buick RG. Tracheal compression caused by achalasia. Pediatr Pulmonol 1989;7:49-51.

9. Givan DC, Scott PH, Eigen H. Achalasia and tracheal obstruction in a child. Eur J Respir Dis 1985;66:70-3.

10. Adachi K, Hayashida M, Toyoshima K. Airway obstruction in a child with esophageal achalasia. Acta Paediatrica Japonica 1989;31:600-4.

11. Panzini L, Traube M. Stridor from tracheal obstruction in a patient with achalasia. Am J Gastroenterol 1993;88:1097-100.

12. Akhter J, Newcomb RW. Tracheal obstruction secondary to esophageal achalasia. J Pediatr Gastroenterol Nutr 1988;7:769-72.

13. Kugelman A, Berkowitz D, Best LA, Bentur L. Upper airway obstruction as a presenting sign of achalasia in childhood. Acta Paediatr 2000;89:356-8.

14. Thomson F, Masters IB, Chang AB. Persistent cough in children and the overuse of medications. J Paediatr Child Health 2002;38:578-81.

15. Kwok SC, O' Loughlin EV, Kakakios AM, van Asperen PP. Wheezy swallow: Poorly responsive 'asthma'. J Paediatr Child Health 2008;44:74-7.

16. Bello CT, Lewin JR, Norris CM, Farrar GE Jr. Achalasia (cardiospasm): Report of a case with extreme and unusual manifestations. Ann Intern Med 1950;32:1184-90. 


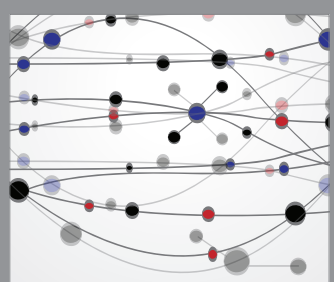

The Scientific World Journal
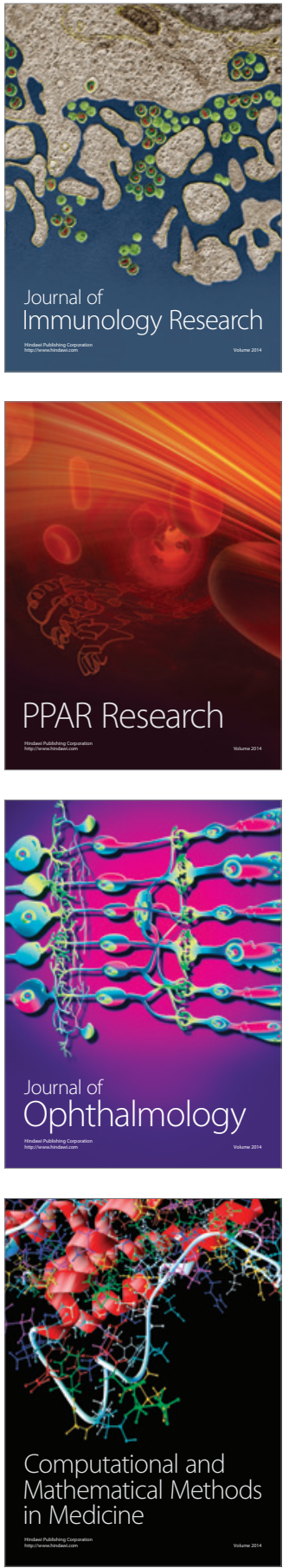

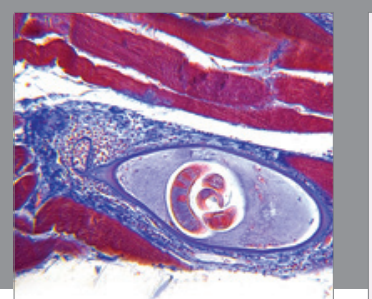

Gastroenterology Research and Practice

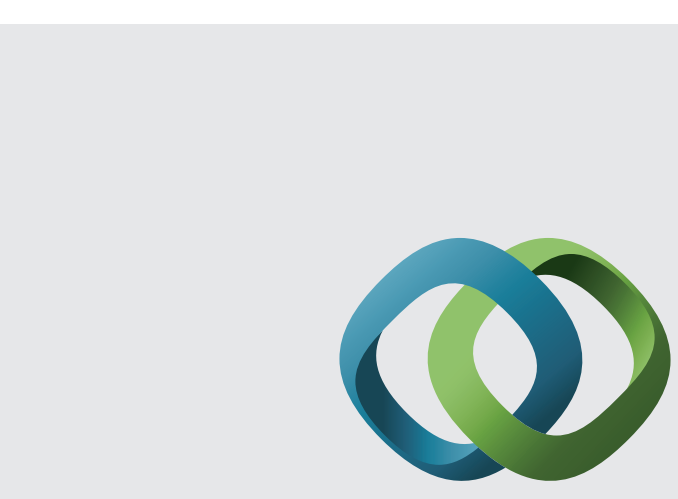

\section{Hindawi}

Submit your manuscripts at

http://www.hindawi.com
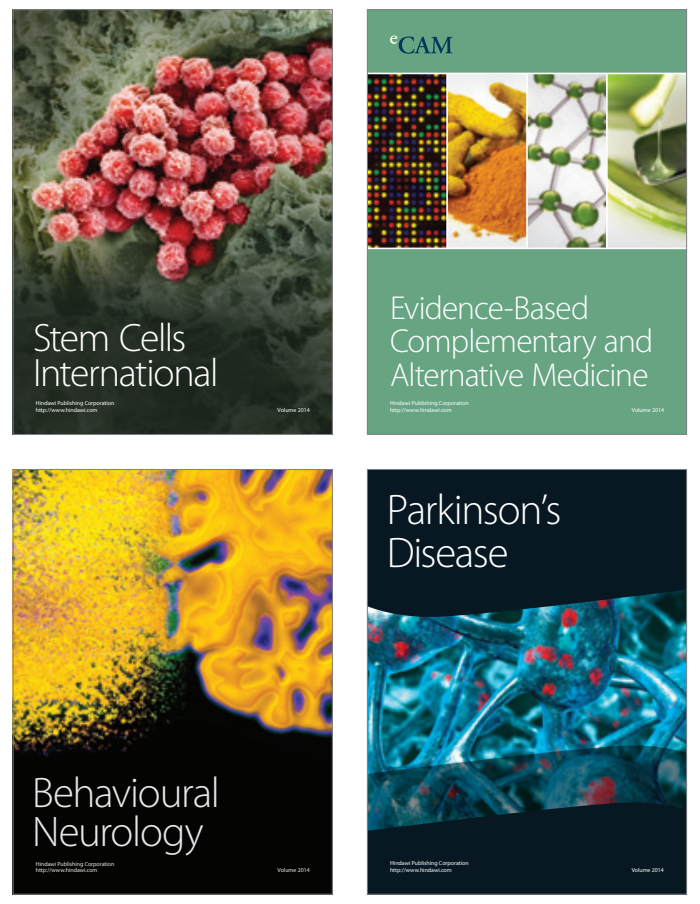
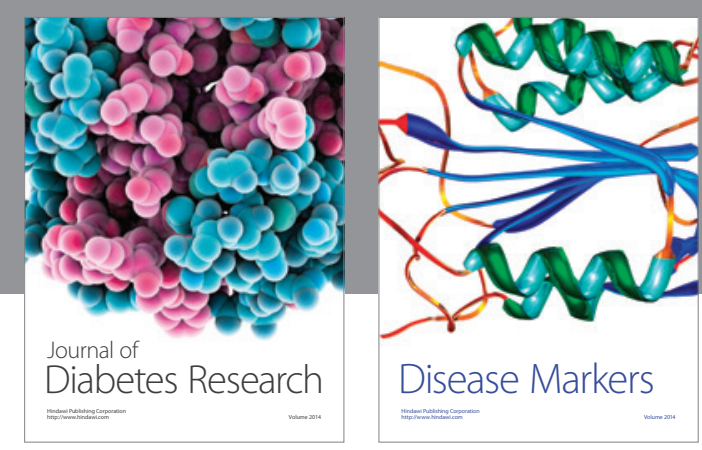

Disease Markers
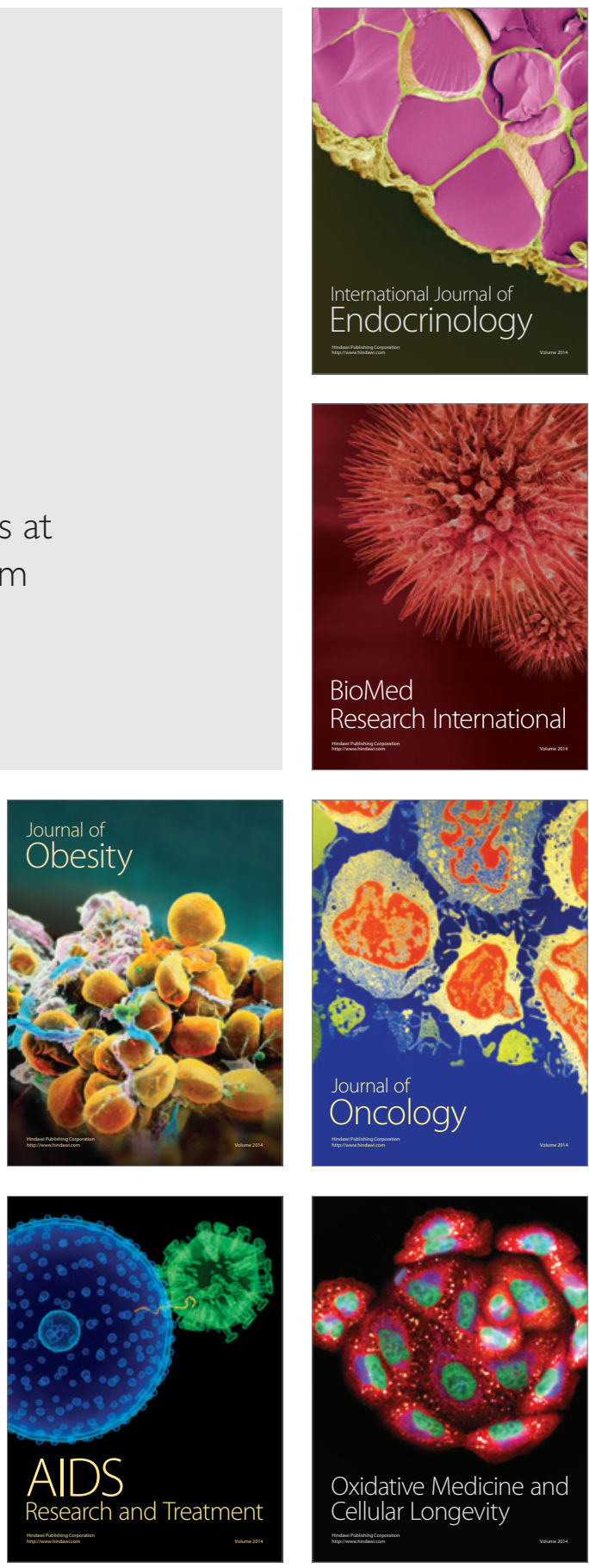